\title{
A complex chitinolytic system in exponentially growing mycelium of Mucor rouxii: properties and function
}

\author{
Dora M. Rast, ${ }^{1 *}$ Markus Horsch, ${ }^{1}$ Rolf FurTer $^{1} \dagger$ and Graham W. Gooday ${ }^{2}$ \\ ${ }^{1}$ Department of Plant Biology, University of Zürich, Zollikerstrasse 107, CH-8008 Zürich, Switzerland \\ ${ }^{2}$ Department of Molecular and Cell Biology, Marischal College, University of Aberdeen, Aberdeen AB9 1AS, UK
}

(Received 13 December 1990; revised 10 August 1991; accepted 6 September 1991)

\begin{abstract}
Enzymological evidence has been sought for the purported involvement of chitinolysis in vegetative growth of filamentous fungi. A procedure has been developed for the production of fast growing and morphologically homogeneous exponential phase mycelium of the non-septate dimorphic zygomycete Mucor rouxii. A partially purified extract of this material has been subjected to gel-permeation chromatography and the chitinolytic activity of eluate fractions has been assessed using colloidal and nascent chitin and 3,4-dinitrophenyl tetra- $N$ acetylchitotetraoside [3,4-DNP-(GlcNAc) $)_{4}$ as substrates. Exponentially growing $\left(t_{\mathrm{d}}=1 \cdot 1 \mathrm{~h}\right)$ mycelium consisting of single short-branched hyphae contains at least seven chitinases. The two particulate ones have not been studied in detail. The soluble chitinases hydrolyse (pseudo)chito-oligomers by random cleavage of internal $\beta$ 1,4-bonds (and not by processing) and have a minimum chain-length requirement of $n=4$. They are clearly distinct from $\beta$ - $N$-acetylglucosaminidase ( $\beta$-GlcNAc'ase) with respect to their chromatographic behaviour, substrate chain-length specificity, inhibition by chitobionolactone oxime $\left(K_{1}=175 \mu \mathrm{M}\right)$, and non-inhibition by the specific $\beta$ GlcNAc'ase inhibitor $N$-acetylglucosaminono-1,5-lactone oxime. Their pH optima are similar (6.5-7.0), and all can hydrolyse 3,4-DNP-(GlcNAc) $)_{4}$ as well as nascent chitin. With respect to their charge, response to protease treatment, behaviour upon gel-permeation chromatography and ability to use colloidal chitin as a substrate, the soluble chitinases do, however, represent two distinct groups. Type $A$ chitinases are acidic, display partial latency, show an unusual affinity to dextran gel and act weakly on colloidal chitin. Type B chitinases are basic (or neutral) and non-zymogenic, do not behave anomalously upon gel filtration and can degrade preformed chitin. An hypothesis is presented for the function of the complex chitinolytic system of the fungal hypha in branching and, possibly, also in apical growth.
\end{abstract}

\section{Introduction}

The basic tenet of Bartnicki-Garcia's model of apical growth in fungi (Bartnicki-Garcia, 1973) is the existence of a delicate balance between the activities of the enzymes catalysing the synthesis and the lysis, respectively, of the microfibrils that confer rigidity to the cell wall. Accordingly, new material is thought to become incorporated into the wall mainly by intussusception. In contrast to this hypothesis, Robertson's view on hyphal tip growth (Robertson, 1968), considerably developed

† Present address: Maag AG Agrochemicals, CH-8157 Dielsdorf $(\mathrm{ZH})$, Switzerland.

Abbreviations: GlcNAc, $N$-acetylglucosamine; 3,4-DNP(GlcNAc) 4, 3,4-dinitrophenyl tetra- $N$-acetyl- $\beta$-D-chitotetraoside; 4NP-GlcNAc, 4-nitrophenyl $N$-acetyl- $\beta$-D-glucosaminide; $\beta$-GlcNAc' ase, $\beta$ - $N$-acetylglucosaminidase (EC 3.2.1.30; including former chitobiase EC 3.2.1.29). and refined by Wessels following his extensive studies with Schizophyllum commune (Wessels, 1986; Wessels et al., 1990), does not involve a localized partial lysis of microfibrils. Instead, all material incorporated at the tip is assumed to have high plasticity and to be laid down at the elongating apex by apposition. It is proposed that the newly added material becomes increasingly rigidified as it is displaced down the margin of the apical dome, in part by linkage of non-crystalline chitin to the $\beta$-glucan acting as the matrix of the wall, in part by its crystallization into fibres (Wessels, 1984).

Bartnicki-Garcia's model requires all chitinous fungi to possess chitinase and for the latter's activity to be displayed during exponential growth. In addition, the enzyme would need to be regulated in such a manner that it would act in a concerted fashion with chitin synthetase, since only such a relationship could provide the very exacting control of the proper chitinase/chitin 
synthetase activity ratio required to prevent excessive lysis, or excessive rigidification, of the tip. A similar relationship should apply also to localized wall synthesis occurring at sites other than the apex, e.g. at places of branch initiation (cf. Rosenberger, 1979; and Discussion).

Despite the wide acceptance of Bartnicki-Garcia's model, the experimental evidence for an involvement of chitinolysis in hyphal tip growth has remained scant. The few observations made relate to post-emergence sporelings of Mucor mucedo (Humphreys \& Gooday, 1984), and to exponential phase cultures of Candida albicans (Barrett-Bee et al., 1982; Barrett-Bee \& Hamilton, 1984), Beauveria bassiana and Nomurea rileyi (Coudron et al., 1984) and Mucor rouxii (Pedraza-Reyes \& Lopez-Romero, 1989). Whether, in the last case, the material providing the enzyme was in full exponential growth and consisted entirely of hyphae, has, however, not been demonstrated convincingly. Moreover, our own unpublished results have indicated a much more complex situation than that described by Pedraza-Reyes $\&$ Lopez-Romero (1989). The present study has been directed towards (1) the establishment of a cultivation procedure for $M$. rouxii that reproducingly yields $\mu_{\max }$ exponential phase mycelium consisting of separate single hyphae only; (2) a survey of the enzymic components of the chitinolytic system, including $\beta$ - $N$-acetylglucosaminidase, present in such cells; and (3) an assessment of some properties that might enable the chitinolytic enzymes to act with chitin synthetase in a co-ordinately regulated manner.

\section{Methods}

Cultivation of fungus. For strain preservation, a culture of Mucor rouxii ATCC 24905 [Rhizopus arrhizus var. rouxii (Calmette) J.J. Ellis] was taken up in water, the material transferred to five flat culture flasks, each containing $20 \mathrm{ml}$ of YPGA medium [0.3\% yeast extract, $1 \%$ peptone, $2 \%$ glucose and $2.5 \%$ agar, all w/v; $\mathrm{pH} 4.5$ (adjusted with $\mathrm{H}_{2} \mathrm{SO}_{4}$ ); surface area $60 \mathrm{~cm}^{2}$ ], and incubated at $27^{\circ} \mathrm{C}$ for $3 \mathrm{~d}$ [according to Bartnicki-Garcia \& Nickerson (1962), Bartnicki-Garcia et al. (1978) and Furter (1985)]. The sporangiospores thus formed were suspended in $10 \mathrm{ml}$ of autoclaved $\left(115^{\circ} \mathrm{C}, 20 \mathrm{~min}\right)$ skimmed milk $(20 \%$, $w / v)$ in sterile-filtered $150 \mathrm{~mm}$-sodium ascorbate; portions of $150 \mu \mathrm{l}$ were transferred to tubes $(50 \times 10 \mathrm{~mm})$ which were closed with a cotton-wool plug, frozen in liquid nitrogen, and lyophilized. The cultures, placed into ampoules $(100 \times 15 \mathrm{~mm})$, were then sealed under nitrogen and stored in the dark at $-20^{\circ} \mathrm{C}$. As judged from the germination rate, determined after several years, supplementation with ascorbate is superior to procedures using solely milk powder, bovine serum albumin in water, or no spacer at all (for quantitative data, see Furter, 1985). All experiments reported here were, thus, performed with an inoculum of cells derived from one single generation of the fungus.

To prepare the inoculum for submerged liquid cultivation, water $(3 \mathrm{ml})$ was added to one lyophilized culture, and a $1 \mathrm{ml}$ portion of the spore suspension was transferred to each of three culture flasks (YPGA, as above), which were incubated at $27^{\circ} \mathrm{C}$ for $3 \mathrm{~d}$. After addition of YPG medium $(10 \mathrm{ml})$, the spores were stripped off with a flexible pipette. The initial cell density in the two to four culture vessels (for type, see below), each containing $600 \mathrm{ml}$ of YPG medium, was $6 \times 10^{5} \mathrm{ml}^{-1}$. They were incubated at $28^{\circ} \mathrm{C}$ in a water bath with a reciprocating shaker operating at $2 \mathrm{~cm}$ travel and 120 strokes $\mathrm{min}^{-1}$, and continuously flushed with a stream of air at $2 \mathrm{ml}$ ( $\mathrm{ml}$ medium $)^{-1}$ $\min ^{-1}(=2$ v.v.m.) and 1 atm overpressure. For the determination of fungal dry matter, samples (10-80 ml), adjusted to the cell mass, were removed aseptically without interrupting aeration, transferred on to Whatman GF/C filters, and washed with a 10 -fold volume of standard buffer (see below). After drying $\left(110^{\circ} \mathrm{C}, 14 \mathrm{~h}\right.$; constant weight), the filters were allowed to cool over $\mathrm{P}_{4} \mathrm{O}_{10}$ in a desiccator, and weighed again.

Culture vessel. A 2 litre flat-bottomed Sovirel Pyrex flask served as the growth chamber, and the screw cap, with three ports (air inlet, air outlet, sampling) drilled through it, as the base of the fermenter head. Tight fitting of the cap to the flask was accomplished by a rubber washer adjusted accordingly. For air filtration, PTFE cylinders $(65 \times 17 \mathrm{~mm} ; 8 \mathrm{~mm}$ i.d.) containing cotton wool plugs were fitted into the openings by means of a PTFE O-ring assembly with windings on either side. Each screw connection was sealed with an O-ring piece (12 mm diam.). Control of the gas throughput was by means of a Kuhnke pneumatic system, with instant push-in fittings and quickrelease couplings. The female part of these was attached to the top of the filtration cylinders, thus establishing the connection to the gas-flow regulator and the flow meter at the outlet, respectively. All tubing was of gas-tight polyamide (PA 11). Sample collection was performed with a syringe carrying a flexible rubber piece.

Isolation of chitinase pools. Apart from minor modifications, the procedure followed the first steps of the standard method for isolating chitosomal chitin synthetase (Bartnicki-Garcia et al., 1978). The hyphae were collected on a sintered glass filter (G3 $7 \mathrm{~cm}$ diam.), washed twice with $100 \mathrm{ml}$ of ice-cold standard buffer $\left(0.05 \mathrm{M}-\mathrm{KH}_{2} \mathrm{PO}_{4}\right.$, $\mathrm{pH} 6.5$, containing $0.01 \mathrm{M}-\mathrm{MgCl}_{2}$ ) and taken almost to dryness. About equal amounts of material were transferred to two $70 \mathrm{ml}$ bottles containing $10 \mathrm{ml}$ of glass beads $(0.5 \mathrm{~mm}$ diam.) and disintegrated in a Braun MSK homogenizer for $3 \times 15 \mathrm{~s}$ at 4000 r.p.m. Samples were strained through cheese cloth, and the beads washed with cold buffer to give a final volume of cell-free homogenate of about $20 \mathrm{ml}$. After centrifugation at $2000 \mathrm{~g}$ for $5 \mathrm{~min}$, mixed membranes and small wall fragments were pelleted at $54500 \mathrm{~g}$ (45 min; Beckman L-8, 30 rotor). The pool of the combined supernatants (total 20-36 ml) was passed through a Bio-Gel A-5m (100-200 mesh) column $(32-40 \mathrm{~cm} \times 2.6 \mathrm{~cm})$ using standard buffer as the eluent. Fractions $(3 \mathrm{ml})$ were collected after the enzyme extract had been drawn into the column. In the determination of retention values $\left(V_{e} / V_{t}\right)$, differences in the large sample sizes have been accounted for. An Amicon ultrafiltration cell fitted with a YM5 membrane served to concentrate pooled eluate fractions.

Enzyme assays. Routine determination of chitinase (EC 3.2.1.14) activities was performed according to the chromogenic assay method of Aribisala \& Gooday (1978). Unless stated otherwise, the reaction mixture consisted of $500 \mu$ l of enzyme preparation, $150 \mu \mathrm{l}$ of test compound solution (or buffer) and $100 \mu \mathrm{l}$ of stock substrate solution (3,4-dinitrophenyl tetra- $N$-acetyl- $\beta$-D-chitotetraoside [3,4-DNP(GlcNAc) $)_{4}$; Koch-Light or Sigma, the latter sold as approx. $60 \%$ by HPLC, $0.5 \mathrm{mg} \mathrm{ml}^{-1}$ ) - all in standard buffer. After incubation at $37^{\circ} \mathrm{C}$ for $30 \mathrm{~min}$, the reaction was stopped by adding $250 \mu \mathrm{l}$ of saturated sodium tetraborate solution. Samples were centrifuged at $15000 \mathrm{~g}\left(r_{\mathrm{av}}\right.$ $4.2 \mathrm{~cm}$ ) for $10 \mathrm{~min}$ at room temperature, and absorbancies were measured at $400 \mathrm{~nm}$. A product calibration curve was established using 3,4-dinitrophenol (Fluka) in the presence of the respective concentrations of all ingredients of the assay medium, in addition to tetraborate. 
Chitinase activities of samples $(50 \mu \mathrm{l})$ with nascent chitin as the substrate were estimated as the reduction caused in net chitin deposition in a standard chitin synthetase reaction mixture (see below) containing either crude (Bio-Gel A-5m void volume) or gradientpurified chitosomes (isolated according to Bartnicki-Garcia et al., 1978) from the same cells. The radiometric assay for chitinase with colloidal chitin as the substrate followed the procedure of Molano et al. (1977), except that $\left[{ }^{14} \mathrm{C}\right]$ - instead of $\left[{ }^{3} \mathrm{H}\right]$ chitin served as the substrate. This was prepared from finely ground chitosan ( $1 \cdot 1 \mathrm{~g}$; Fluka) using $250 \mu \mathrm{Ci}(9 \cdot 25 \mathrm{MBq})\left[1-^{-14} \mathrm{C}\right]$ acetic anhydride (Amersham). The reaction mixture contained $0.5 \mathrm{ml}$ enzyme preparation and $0.5 \mathrm{ml}$ (about $5 \mathrm{mg}$ ) $\left[{ }^{14} \mathrm{C}\right]$ chitin suspension $(264717 \pm 5428$ d.p.m.; four experiments); incubation was at $30^{\circ} \mathrm{C}$ for $24 \mathrm{~h}$, with vigorous shaking. After adding TCA $(400 \mu \mathrm{l} ; 10 \% \mathrm{w} / \mathrm{v})$, the samples were centrifuged as above, and the radioactivity of their supernatant fractions $(200 \mu \mathrm{l}$ portion) counted in $4 \mathrm{ml}$ of Aquasol-2 (NEN) scintillation cocktail. Assays were run in triplicate.

Activities of $\beta$ - $N$-acetylglucosaminidase $\quad(\beta$-GlcNAc'ase; EC 3.2.1.30) were determined under the same conditions as used for the chromogenic chitinase assay, with 4-nitrophenyl $N$-acetyl- $\beta$-Dglucosaminide (4-NP-GlcNAc; Sigma) as substrate (Borooah et al., 1961).

The chitin synthetase (EC 2.4.1.16) assay mixture contained, in a total volume of $125 \mu \mathrm{l}$ of buffer, enzyme preparation $(50 \mu \mathrm{l})$, Rennilase (a crude acid protease, $125 \mu \mathrm{g}$ ) and $1 \mathrm{~mm}$-UDP-[U- $\left.{ }^{14} \mathrm{C}\right] \mathrm{GlcNAc}$ (Amersham; 55000 d.p.m.) and $20 \mathrm{mM}-\mathrm{GlcNAc}$; the incubation temperature was $28^{\circ} \mathrm{C}$ and the reaction time $30-60 \mathrm{~min}$. Chitin deposition was determined by a filtration method (Ruiz-Herrera \& Bartnicki-Garcia, 1976). When nascent chitin was used to estimate chitinase activities (Lopez-Romero et al., 1982), the protease amounts were 'high' $\left(1000 \mu \mathrm{g} \mathrm{ml}^{-1}\right)$, 'low' $\left(10 \mu \mathrm{g} \mathrm{ml}^{-1}\right)$ or nil.

The assay conditions for $\beta$-galactosidase [used as a marker for molecular mass determination; mol. mass $=520 \mathrm{kDa}$ (Sund \& Weber, 1963)] were as described previously (Hänseler et al., 1983).

Protein was measured with the Bio-Rad dye reagent (Bradford, 1976; microprocedure) using bovine serum albumin as the reference.

Fast protein liquid chromatography (FPLC). Separation was performed in a Pharmacia FPLC apparatus equipped with a Mono Q HR $5 / 5$ column, using 20 mM-bis-Tris propane, pH 6.8, and an $\mathrm{NaCl}$ gradient for elution. The sample size was $2 \mathrm{ml}$, the flow rate $1 \mathrm{ml} \mathrm{min} \mathrm{m}^{-1}$, and the fraction size $1 \mathrm{ml}$. Protein values are given in absorption units full scale (AUFS). Chitinase activities were assessed with $400 \mu \mathrm{l}$ samples under the standard assay conditions. The incubation time was $60 \mathrm{~min}$.

Special biochemicals. 4-Nitrophenyl $\beta-N, N^{\prime}$-diacetylchitobioside was purchased from Sigma. The 3,4-dinitrophenyl $\beta$-glycosides of monoand oligomeric $\beta$-1,4-linked $N$-acetyl-D-glucosamine $(n=1-5)$, used for some detailed analyses, were obtained following a modification (L. Hoesch, I. Travnicek \& D. M. Rast, unpublished) of the procedure of Ballardie et al. (1977). According to TLC, their purity was $98 \%$; structural identities were derived from ${ }^{1} \mathrm{H}$-NMR and - in part - mass spectroscopy also. For the synthesis of $\mathrm{N}$-acetylglucosaminono- and the corresponding chitobionolactone oxime, refer to Beer et al., 1990. Rennilase was a gift from Schweizerische Ferment AG (Basel, Switzerland).

\section{Results}

Growth kinetics and morphology of experimental material

Information on the growth kinetics of large batches of $M$. rouxii hyphae in submerged liquid culture, indispen-

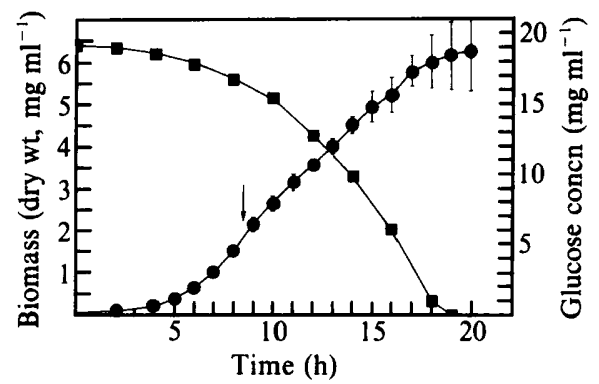

Fig. 1. Kinetics of growth (O) and glucose utilization ( $\square$ ) of $M$. rouxii in an aerobic submerged liquid cultivation system (for details see Methods). The arrow indicates the time at which the cells were harvested for the determination of chitinase activities. Values represent the mean $( \pm S D)$ of three independent experiments.

sable in the context of this investigation, had previously been lacking. Therefore, the procedure described by Bartnicki-Garcia et al. (1978) was standardized, with particular attention being paid to factors having an effect on the morphology of the cells, especially at high growth rates and high cell density, i.e. oxygen supply, carbon dioxide concentration and temperature (BartnickiGarcia \& Nickerson, 1962; Furter, 1985).

The medium was aerated at a very high flow rate $(2$ v.v.m.). This was to optimize dissolved oxygen concentration, the process variable most likely to restrict the growth rate in the exponential phase, to remove respiratory carbon dioxide efficiently, and to provide some gentle stirring, in addition to shaking. This cultivation system was subsequently found to display high reproducibility with respect to growth rate $\left[\mu_{\max }\right.$ $\left(\mathrm{h}^{-1}\right)=0.62 \pm 0.02$; Furter, 1985], growth phase as a function of incubation time (Fig. 1) and morphology of the cells (Fig. 2). Most importantly, exponential phase cultures exhibited purely filamentous growth (Fig. $2 d, e$ ). The experimental material, exponential phase hyphae with short branches (Fig. $2 d$ ), originated from a medium that still contained more than $80 \%$ of the glucose supplied (20 mg ml-1; Fig. 1).

\section{Presence of an array of chitinolytic enzymes in exponential phase hyphae}

When the $54500 \mathrm{~g}$ supernatant was subjected to gel permeation chromatography and fractions tested for activity towards colloidal chitin, chitinolytic activities with $V_{\mathrm{e}} / V_{\mathrm{t}}$ values of around $0.40,0.85,1.20$ (shoulder), 1.45 and 1.65 were detected (Fig. 3). However, their affinities to this substrate were low, since in $24 \mathrm{~h}$ they had digested only $1 \cdot 2,6 \cdot 6,1 \cdot 4,0.5$ and $0.3 \%$, respectively, of the total amount supplied, corresponding to a chitinolytic activity, in GlcNAc equivalents, of $0.46 \mathrm{nmol} \mathrm{min}^{-1} \mathrm{ml}^{-1}$ for the major peak. This precluded 

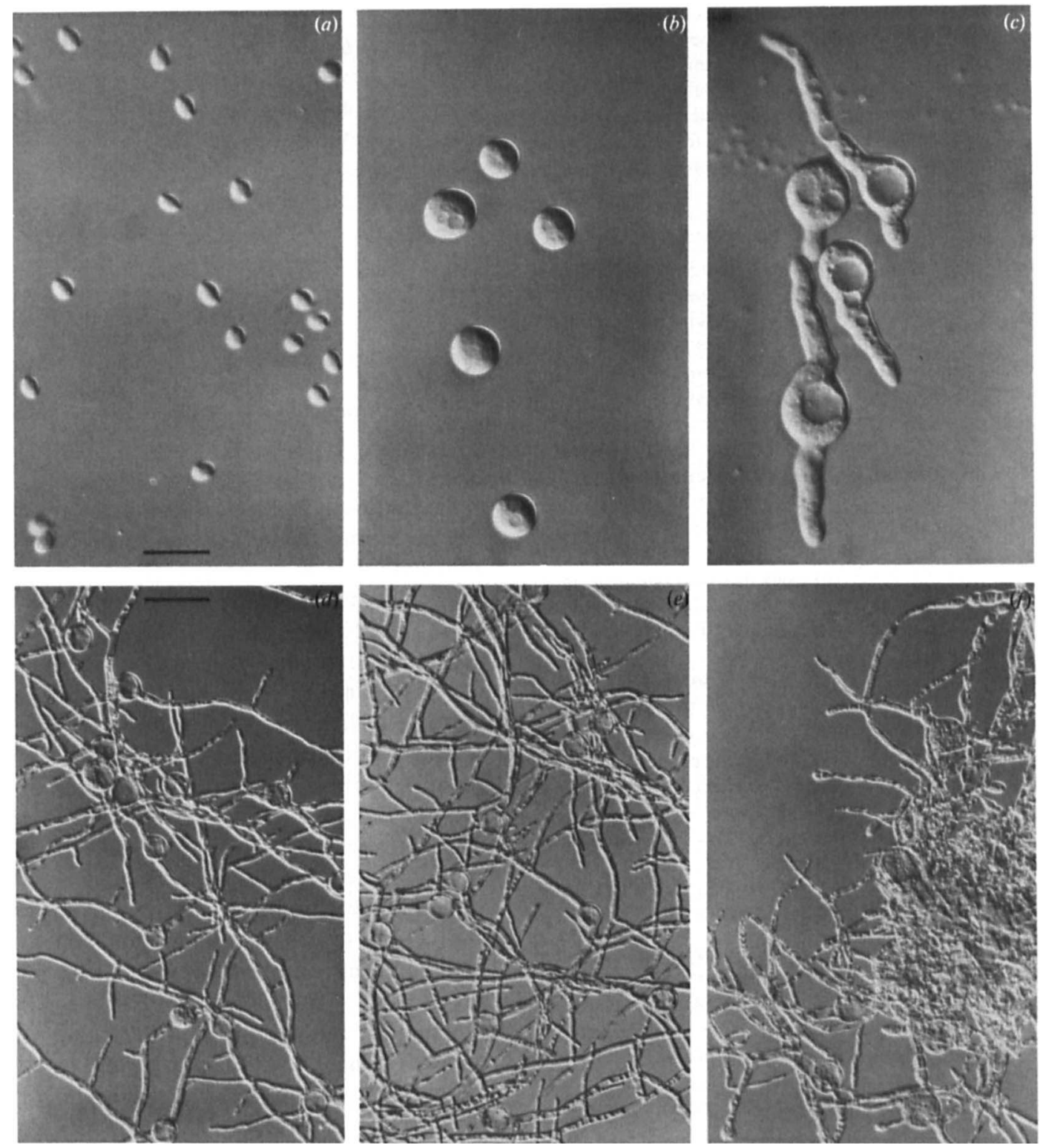

Fig. 2. Cell forms representative for $M$. rouxii grown in an aerobic submerged liquid cultivation system (see Fig. 1 and Methods; Nomarski differential interference contrast micrographs). (a) Sporangiospores (inoculum; $0 \mathrm{~h}$ ); $(b)$ spherical cells (4.5 h); (c) germlings (mostly bipolar; $6 \mathrm{~h}) ;(d, e)$ exponential phase hyphae $(8.5$ and $11.5 \mathrm{~h})$, with a preponderance of short and somewhat longer branches, respectively; $(f)$ deceleration-phase mycelium $(16 \mathrm{~h})$, with intermingling of hyphae, tendency of tips to swell and fairly frequent arthrospore formation. For $(a)-(c)$ samples of the spore suspensions were centrifuged prior to taking the pictures, whereas for $(d)-(f)$ they were viewed directly. The bars represent 20 and $50 \mu \mathrm{m}$ in the upper and the lower row, respectively.

the expeditious use of colloidal chitin for monitoring column eluates and also pointed to a substrate specificity that might be met more closely by nascent chitin and/or chito-oligomers.

The nascent chitin assay for chitinase is a somewhat peculiar test as it yields negative peaks in those chitinase fractions which also contain chitin synthetase with an activity exceeding the $V_{\max }$ of the chitinase to be assessed. In addition, chitinase could, perhaps, be inhibited at high substrate concentrations, especially since assay conditions are maximized for net chitin deposition, and not hydrolysis. These considerations evidently relate to the present case, as fractions up to $V_{\mathrm{e}} / V_{\mathrm{t}}=\mathbf{0 . 7 5}$ did contain chitin synthetase (Fig. 3): there is the chitosomal chitin synthetase (105S, in the void volume), and a chitin synthetase with the same retention behaviour as $\beta$-galactosidase (16S). The existence of an additional chitin synthetase species, of lower molecular 


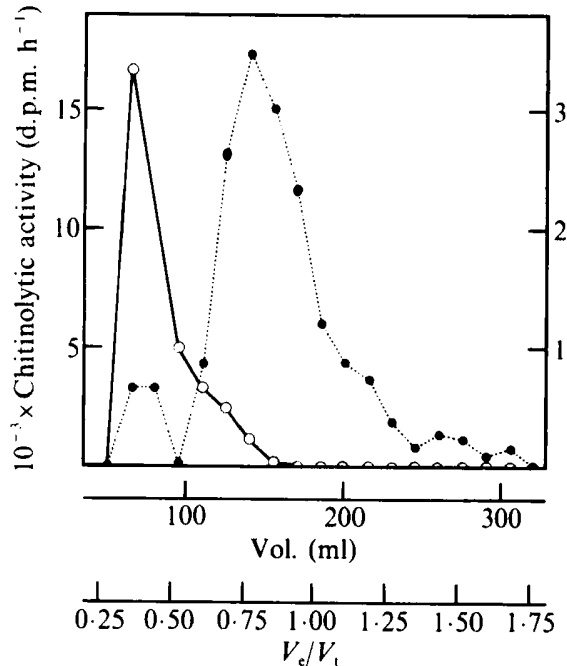

Fig. 3. Permeation chromatography of the microsomes/soluble enzymes fraction of an extract from $M$. rouxii exponential phase hyphae, using colloidal chitin as the substrate. To mark the region of the void volume and to estimate the minimum extent to which there is cooccurrence of chitinase $(O)$ and chitin synthetase $(O)$, the elution profile of the latter was also monitored. Due to the presence of chitinase in a large proportion of the fractions collected, their chitin synthetase activity is referred to as 'net chitin deposition'. Experimental details are given in Methods.

mass, is indicated by the regular occurrence of small but distinct negative peaks in the $1.0-1.5$ region of the profile (Fig. 4). Nevertheless, the 'nascent chitin chitinase' test can provide qualitative information. Indeed, when column eluates were checked for activity towards nascent chitin formed by native chitin synthetase, chitinolysis was detected. The positive profile consisted of three components, located in the 0.75-1.00 and the $1.15-1.50$ regions and at 1.60 (Fig. $4 a, b$ ). With proteolytically activated chitin synthetase there was a more complex situation, suci that peaks appeared that corresponded to only part of the extended plateaus of activity seen with the native enzymes. This suggests microheterogeneity of the chitinases concerned. Additionally, activities became detectable at places where negative peaks (i.e. net chitin deposition) had been displayed before (at 0.7, 1.1 and 1.6; Fig. 4a). Different conditions ('low' protease treatment and a larger column packing) yielded basically the same result: there were two chitinolytic entities with retention values near 0.7 and 1.00 , respectively, and possibly four with $V_{\mathrm{e}} / V_{\mathrm{t}}$ exceeding 1.00 (Fig. $4 b$ ). The latter chitinases might be considered as minor in comparison with those occurring in the 0.7-1.00 region of the profile, but they are of equal importance when account is taken of the very different protein values, which ranged from about 300 to 40,10 and $5 \mu \mathrm{g} \mathrm{m}^{-1}$ at $V_{\mathrm{e}} / V_{\mathrm{t}}=0.75,1.00,1.25$ and 1.50 ,
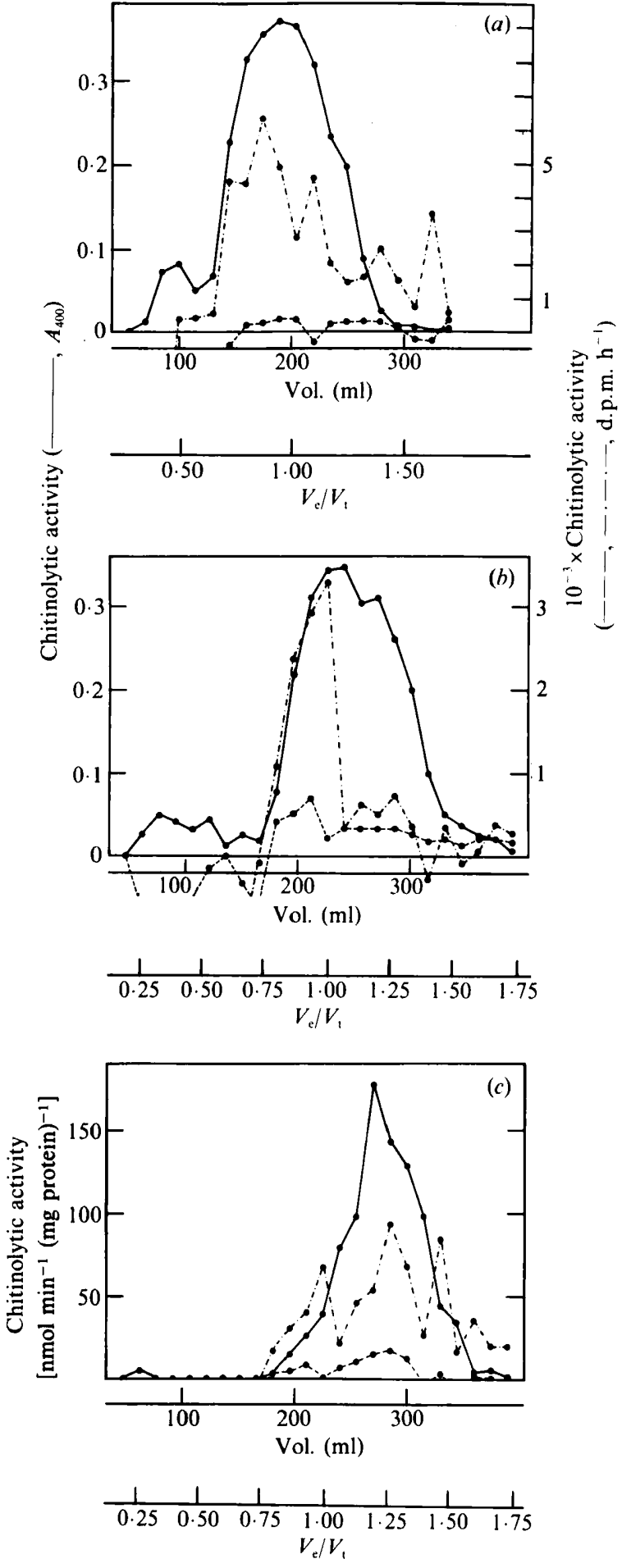

Fig. 4. Presence of various chitinases in exponential phase hyphae of $M$. rouxii as shown after gel-permeation chromatography of the microsomes/soluble enzymes portion of a cell extract and monitoring of eluate fractions with nascent chitin, synthesized by native (---) or protease-treated (-.-.-) chitin synthetase, and the chito-oligomer analogue 3,4-DNP-(GlcNAc) ${ }_{4}(--)$. In $(a)$ the concentration of the activating protease was 'high'; in $(b)$ and $(c)$ it was 'low' (see Methods); $(c)$, based on the data of $(b)$, expresses specific activities obtained using the three different assays. 


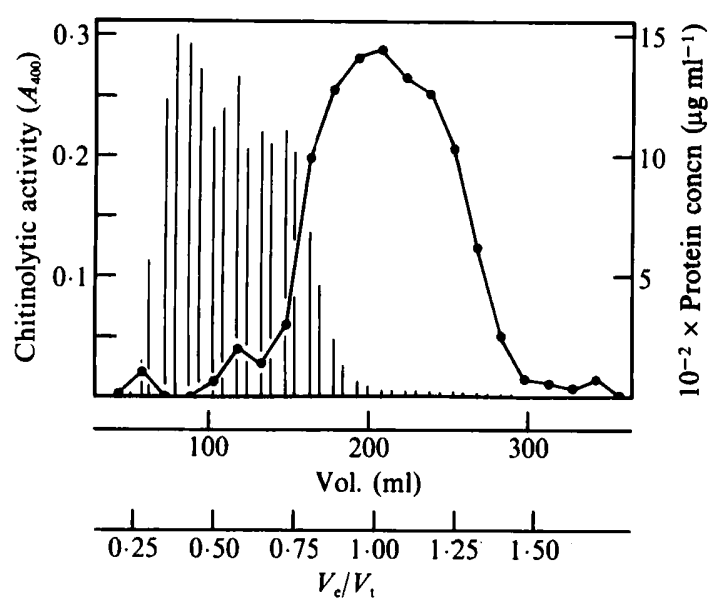

Fig. 5. Gel-permeation chromatography elution profiles of protein (vertical lines) and chitinases (O) present in the microsomes/soluble enzymes fraction of exponential phase hyphae of $M$. rouxii, monitored - respectively - with a dye reagent and 3,4-DNP-(GlcNAc) ${ }_{4}$ as the substrate in the presence of 'high' protease. Technical details are given in Methods.

respectively (for a protein elution profile, see Fig. 5); to emphasize this, values for specific activities are presented separately (Fig. $4 c$ ). When the chitin-generating system was activated proteolytically, the nascent chitin degrading activity of all of the chitinases observed increased sharply (Fig. 4).

Upon testing for chitinolytic activity with a chromogenic analogue of chitopentaose, 3,4-DNP-(GlcNAc) ${ }_{4}$, the elution profile was dominated by a large, broad, and undoubtedly composite peak, with the maximum near $V_{\mathrm{e}} / V_{\mathrm{t}}=1.00$, which displayed an extended shoulder in the 1.4-1.6 region (Fig. $4 a, b$ ). In addition, there was always a small peak near 0.5 ; the corresponding chitinase had the same elution behaviour as $\beta$-galactosidase. The chromogenic assay proved to be more sensitive than the nascent chitin assay (about 10 times when performed in the absence of protease: Fig. $4 c$ ). Furthermore, it is evident from Fig. 4 that the former assay also probes for chitinases that are not (fully) accounted for by the latter assay, particularly when the chitin substrate is generated by the proteolytically activated enzyme. The presence of yet another chitinase, in the void volume, could be shown clearly only when chromatography was performed with the largest column used (see Methods and Fig. $4 b$, first peak), or when testing for chitinases was done in the presence of 'high' protease (Fig. 5). This treatment caused the main peak to become flattened on top and extended on either slope (cf. Fig. $4 a$ with Fig. 5), and its shape changed such as would be the case if it consisted of chitinases dissimilar in zymogenicity (a more detailed consideration of the different response of main peak chitinases to protease treatment is given in the next section). Occasionally, a small peak occurred at

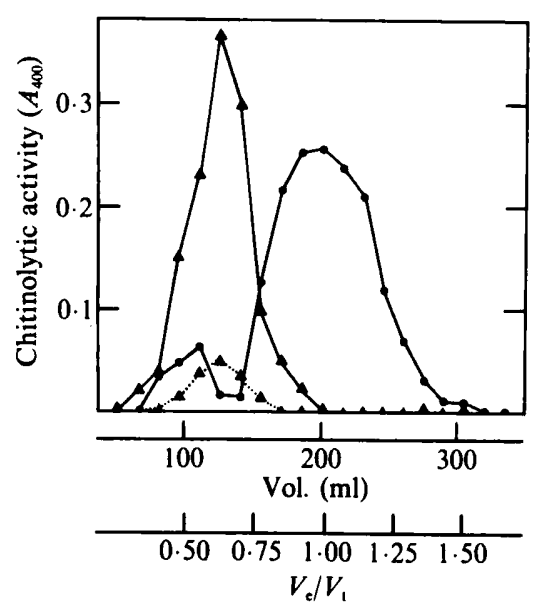

Fig. 6. Co-occurrence of $\beta$-GlcNAc'ase $(A)$ and chitinase $(O)$ in the microsomes/soluble enzymes fraction of exponential phase hyphae of $M$. rouxii, as demonstrated by gel-permeation chromatography using 4NP-GlcNAc $(\boldsymbol{A}-\mathbf{A})$ or the corresponding chitobioside $(\boldsymbol{\Lambda} \ldots \mathbf{\Delta})$ and 3,4-DNP-(GlcNAc) $)_{4}(-)$ ) as the substrates.

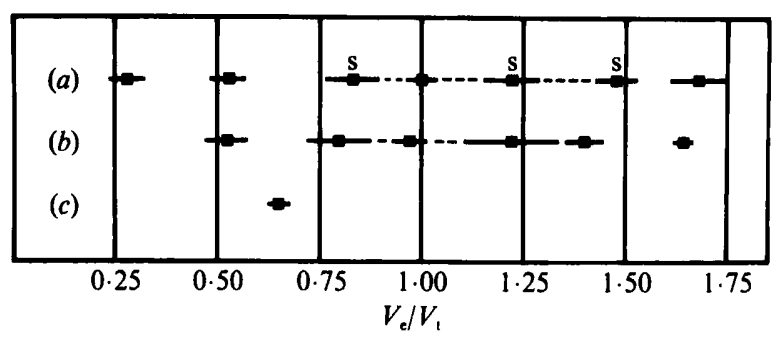

Fig. 7. Designation of chitinolytic entities present in the microsomes/ soluble enzymes fraction of $M$. rouxii exponential phase hyphae based on behaviour on gel-permeation chromatography. Mean relative retention volumes of peak (or shoulder, s) maxima \pm SD values (three to twenty experiments) are given. Data are based on 3,4-DNP-(GlcNAc) (a), nascent chitin (b) and 4-NP-GlcNAc (c) as the enzyme substrates, as well as on a wide range of sample size and column length combinations (see Methods). -.-, No base line separation.

$V_{\mathrm{e}} / V_{\mathrm{t}}$ around 0.65 (Fig. $4 b$ ), but this was probably not due to the presence of a chitinase (see below).

To ascertain whether the enzymes hydrolysing 3,4DNP-(GlcNAc) ${ }_{4}$ were, indeed, chitinases, and not simply $\beta$ - $N$-acetylglucosaminidases having a substrate specificity extending to chito-oligosaccharides, fractions were tested against 4-NP-GlcNAc, the commonly used chromogenic analogue of the presumptive natural substrate of $\beta$-GlcNAc'ase, $N, N^{\prime}$-diacetylchitobiose. The main peak chitinases were clearly distinct from the 4NP-GlcNAc-hydrolysing entity (Fig. 6) which displayed a sharp peak maximum at $V_{\mathrm{e}} / V_{\mathrm{t}}$ close to 0.65 . Basically the same result was obtained using the corresponding bioside, but the activity was only $10-15 \%$ of that elicited by the monoside with the purified $\beta$-GlcNAc'ase from the same fungal material. The presence of a highly active 


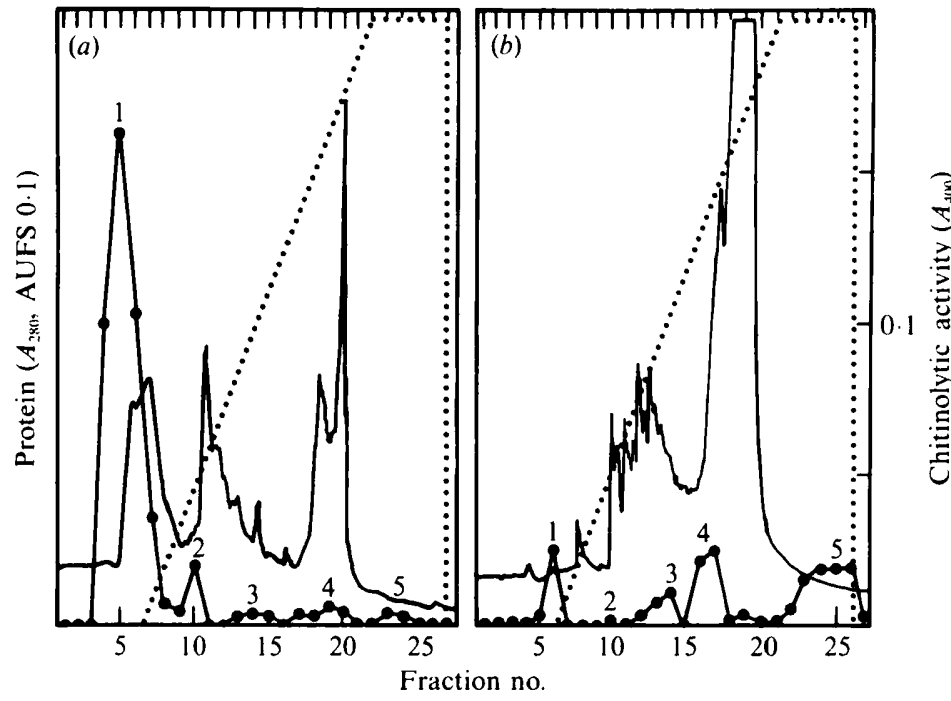

Fig. 8. Anion-exchange chromatography (FPLC) of chitinases from $M$. rouxii exponential phase hyphae. - , Protein $\left(A_{280}\right.$ recorded as absorption units full scale, AUFS);, chitinolytic activity; $\ldots, \mathrm{NaCl}$ gradient $(0-1 \mathrm{M})$. The results reported here relate to the gel-permeation chromatography experiment depicted in Fig. $4(b)$; eluate fractions with $V_{e} / V_{\mathrm{t}}=1.08-1.19(a)$ and $1.61-1.72(b)$ were pooled. Enzyme activity was determined by the chromogenic assay procedure. The chromatograms shown are representative for one out of six analogous experiments. Peak assignments (cf. Fig. 7): 1, chitinase $1.00 ; 2$ and 3 , components of the chitinase 1.20 'complex'; 4, chitinase $1.45 ; 5$, chitinase 1.65 .
$\beta$-GlcNAc'ase in the extract and the fact that some of the commercial 3,4-DNP-(GlcNAc) ${ }_{4}$ batches used to probe the eluate fractions for chitinase activity contained a substantial proportion of the bioside (L. Hoesch, I. Travnicek \& D. M. Rast, unpublished; see also Methods) may explain the erratic occurrence of the minor, probably 'false' chitinase peak at $0 \cdot 65$ (cf. above and Fig. $4 b$ ).

A summary, together with a statistical evaluation, of all gel-permeation chromatography experiments is given in Fig. 7. The combined evidence shows that exponential phase $M$. rouxii hyphae display a complex chitinolytic system composed of at least seven chitinases, besides $\beta$ GlcNAc'ase. Hereafter, the chitinases will be referred to by their approximate mean $V_{\mathrm{e}} / V_{\mathrm{t}}$ values e.g. chitinase 1.00 . Since some of them are microheterogeneous (see above), these assignments do not necessarily refer to one single enzyme, but in some cases to 'complexes' of very closely associated chitinases. Pooled fractions of chitinases $0.75-1.00$ and chitinases $1.01-1.25$ had specific activities [3,4-DNP-(GlcNAc) $)_{4}$; no protease] of $6.75 \pm 4.25$ and $117.12 \pm 51.66 \mathrm{nmol} \min ^{-1}$ (mg protein $)^{-1}$; respectively (five independent isolations).

The multiplicity of chitinolytic entities present in exponential phase hyphae was confirmed by FPLC of pooled fractions resulting from permeation chromatography. As chitinases with $V_{\mathrm{e}} / V_{\mathrm{t}}$ values up to 0.80 eluted together with $93 \%$ of the total microsomes/soluble enzymes protein of the cells (Fig. 5), examination of these was $a$ priori not considered to be meaningful at this point. Even so, pools of chitinase peak (shoulder) fractions with $V_{\mathrm{e}} / V_{\mathrm{t}} \geqslant 1$ would still be expected to be contaminated by other chitinolytic entities, owing to the broad and overlapping elution profiles, as evident particularly with the substrate 3,4-DNP-(GlcNAc) ${ }_{4}$ and nascent chitin synthesized by the zymogenic form of the synthetase (Fig. 4). Indeed, despite the large number of FPLC analyses performed with pooled chitinase fractions representing the entire spectrum from $V_{\mathrm{e}} / V_{\mathrm{t}}=1.00-1.70$ (Fig. 8), attempts to obtain chromatograms clearly displaying only one single chitinase entity were never successful. Assignment of FPLC peaks to the chitinases revealed by permeation chromatography (Fig. 7) was, nonetheless, possible. Thus, peak 1 represents chitinase 1.00 . It usually appeared to contain some chitinase 0.80 (cf. Fig. 4), since $0.85-0.95$ pools produce a very large, somewhat asymmetric chitinase activity peak with the steeper slope towards the higher elution volume. As expected, the corresponding protein peak was enormous and practically unresolved (not shown). This was not so with chitinase preparations of higher $V_{\mathrm{e}} / V_{\mathrm{t}}$ in which chitinase 1.00 could have been present only as a very minor contaminant. Here the activity eluted sharply, with a minute, distinct protein peak (Fig. 8). Peaks 2 and 3 represent the chitinase 1.20 'complex' (see above and Fig. $4 b$ ). There was no indication for a reversal of the order of elution of the two chitinases concerned (cf. Pedraza-Reyes \& Lopez-Romero, 1989) upon anion-exchange chromatography as compared with permeation chromatography, since peak 2 , which was always quite sharp, disappeared first when pools of fractions with successively higher $V_{\mathrm{e}} / V_{\mathrm{t}}$ values were analysed. Conversely, peak 5 correspondingly increased in size and represented the major single chitinase activity in $V_{\mathrm{e}} / V_{\mathrm{t}}$ pools of approximately $1 \cdot 6-1 \cdot 7$. This situation leaves peak 4 to be assigned to chitinase 1.45 . 
Properties of components of the exponential phase chitinolytic system of $M$. rouxii hyphae

Retention on chromatography matrices and charge. Proteins with $V_{\mathrm{e}} / V_{\mathrm{t}} \geqslant 1$, such as chitinase species 1.00-1.60, behave anomalously on gel filtration being separated by molecular sieving and an additional process leading to their retardation. This fortuitously resulted in a better purification of these chitinases. On the other hand, their atypical behaviour precludes a reliable estimation of their molecular masses by permeation chromatography, at least with agarose-based gels. If a globular shape and non-interaction of chitinase 1.00 with the gel was assumed, its molecular mass would be about $80 \mathrm{kDa}$.

As evidenced by FPLC-directed anion-exchange chromatography (Fig. 8), chitinase 1.00 and the contaminating 0.80 form were basic or neutral, whereas the chitinases with $V_{\mathrm{e}} / V_{\mathrm{t}}>1.00$ were acidic. This also holds for $\beta$-GlcNAc'ase (separately purified) which emerged from the FPLC column as a sharp peak at a nominal $\mathrm{NaCl}$ concentration of 0.39 (chromatogram not shown). If present as a contaminant in the chitinase pools collected following gel-permeation chromatography it would be situated between the two components of the chitinase 1.20 'complex' (Fig. 8, peaks 2 and 3), with mean $\mathrm{NaCl}$ elution values of 0.23 and 0.51 , respectively. Some of these chitinases behave anomalously not only upon gel filtration, but also on anion-exchange chromatography, in that their elution profiles are very broad for a high performance separation method (Fig. 8, peaks 35 ). This could be due to microheterogeneity of the enzymes, arising from individual molecules differing slightly in charge, or be a consequence of some unspecific interaction with the column matrix (for details see Discussion).

pH optima. Using MES and TES buffers and 3,4DNP-(GlcNAc) ${ }_{4}$ as the substrate, the $\mathrm{pH}$ dependence of activity was measured at half intervals from $5 \cdot 0-7.5$ for chitinases 1.00 (five experiments) and 1.20 (two experiments). Chitinases 1.45 and -1.60 were not tested. Chitinase 1.00 showed a maximum at $\mathrm{pH} 7.00$ and the $\mathrm{pH}$ curve was very flat. In contrast to this, chitinase 1.20 displayed a sharper activity curve with the maximum at $\mathrm{pH}$ 6.5. The activity of $\beta$-GlcNAc'ase was likewise highest at $6 \cdot 5$.

Latency. The increases observed in the nascent chitindegrading activity of all the chitinases upon proteolytic stimulation of the chitin-generating system (Fig. 4), which at low protease concentrations were particularly prominent for chitinases $0.75-1.05$ (Fig. $4 b$ ), could be due either to a limited availability of the substrate with only the native chitin synthetase affording it, or to zymogenicity of (some of) the chitinases themselves. The
Table 1. Activities of chitinase pools collected following gelpermeation chromatography of a partially purified extract from $M$. rouxii exponential phase hyphae with the 3,4-DNP$\beta$-glycosides of monomeric and oligomeric $\beta$-1,4-linked GlcNAc as the substrates.

$100 \%$ 3,4-DNP-releasing activity represents $A_{400}$ values of $0.077,0.096$ and 0.091 for the respective pooled chitinase fractions; specific activities [ $\mathrm{nmol} \mathrm{min}^{-1}(\mathrm{mg} \text { protein })^{-1}$ ] with the native enzymes were 2,35 and 206, respectively. Means \pm SD values (same pools, but three independent experiments) are given.

\begin{tabular}{|c|c|c|c|}
\hline \multirow{2}{*}{$\begin{array}{l}\text { Substrate } \\
(500 \mu \mathrm{M})\end{array}$} & \multicolumn{3}{|c|}{$\begin{array}{c}\text { 3,4-DNP-releasing activity (\%) } \\
\text { of chitinase fractions with } V_{\mathrm{e}} / V_{\mathrm{t}} \\
\text { values of: }\end{array}$} \\
\hline & $0.76-0.87$ & $1.03-1 \cdot 13$ & $1 \cdot 30-1 \cdot 40$ \\
\hline 3,4-DNP-GlcNAc & $81 \pm 5$ & 0 & 0 \\
\hline 3,4-DNP-(GlcNAc) $)_{2}$ & $24 \pm 1$ & 0 & 0 \\
\hline 3,4-DNP-(GlcNAc) ${ }_{3}$ & $109 \pm 10$ & $85 \pm 4$ & $27 \pm 4$ \\
\hline 3,4-DNP-(GlcNAc) $)_{4}$ & $100 \pm 4$ & $100 \pm 5$ & $100 \pm 6$ \\
\hline 3,4-DNP-(GlcNAc) & $55 \pm 12$ & $44 \pm 3$ & $48 \pm 9$ \\
\hline
\end{tabular}

nascent chitin chitinase assay does not allow a distinction to be made between the two possibilities. Therefore, chitinase pools (concentrated over an Amicon XM-50membrane) were treated with protease (up to $500 \mu \mathrm{g}$ $\mathrm{ml}^{-1}$ ) and provided with the chromogenic substrate. Chitinases with $V_{\mathrm{e}} / V_{\mathrm{t}} \geqslant 1.25$ experienced always a sharp stimulation; maximum activation, $190-260 \%$, occurred at protease concentrations between 100 and $300 \mu \mathrm{g} \mathrm{ml}^{-1}$. With the other soluble chitinases, the same protease treatment caused a concentration-dependent gradual decline of activity; the maximum inhibition was $40 \%$ (at $500 \mu \mathrm{g} \mathrm{ml}^{-1}$ ).

Chain length specificity with soluble chromogenic substrates and mechanism of hydrolysis (endo-vs exo-activity). The $M$. rouxii $\beta$-GlcNAc'ase (Bio-Gel pool) proved to be fairly specific for monomeric 4-NP- $N$-acetylglucosaminide, since the activity with the corresponding $N, N^{\prime}$ diacetylchitobioside was only about $15 \%$ of that of the former (Fig. 6) and there was no activity with higher analogues (Linder, 1987). Basically the same result was obtained using the corresponding substrate series with 3,4-DNP as the chromogenic residue (see Table 1); the activity with the bioside amounted to $11 \pm 4 \%$ (three experiments) of that displayed with the monoside, and higher analogues were not hydrolysed (Linder, 1987). Chitinases with $V_{\mathrm{e}} / V_{\mathrm{t}}>1$, which were of a higher purity than those with lower elution volumes, did not accept either of these $\beta$-GlcNAc'ase substrates (Table 1), but were reactive with higher GIcNAc analogues, a (pseudo)chitotetraose evidently meeting the minimum requirement for binding. The same held for chitinases with $V_{\mathrm{e}} / V_{\mathrm{t}}<1$ (Table 1). The observed release of some 3,4-DNP in the presence of the bioside appears to be an 
experimental artefact that is due to contamination of the chitinase preparation with $\beta$-GlcNAc'ase (Fig. 6 and results of Table 1 with the monoside) and should not be construed as evidence for the substrate specificity of these chitinases extending to (pseudo)chitotriose. Because of the transglycosylating activity of $\beta$-glycosidases (cf. Sinnott, 1987) it may be assumed that the $\beta$ GlcNAc'ase synthesized some 3,4-DNP-(GlcNAc) ${ }_{3}$ which, in turn, served as a substrate of the chitinases concerned.

Whereas, by definition, $\beta$-GlcNAc'ase represents an enzyme with exo-activity, the situation is not so clear-cut with chitinase. Although this is generally held to degrade chitin by random cleavage of internal $\beta$-1,4-bonds (endotype of action), producing first chito-oligomers of varying lengths and, finally, diacetylchitobiose, the possibility cannot be ruled out that some chitinases could follow a processive degradation mechanism (exo-type of activity) by successively removing chitobiose units, starting at the non-reducing end of the chitin chain (see Kramer \& Koga, 1986; Robbins et al., 1988). In order to characterize $M$. rouxii exponential phase chitinases with respect to the random vs processive mechanism of hydrolysis, their activity was assessed with 3,4-DNP derivatives of chito-oligomers (formal $n=4-6$; Table 1). This approach takes advantage of the high tolerance for the leaving group of $\beta$-glycosidases in general (Sinnott, 1987), and the chitinases concerned in particular [similar rates of hydrolysis with 3,4-DNP-(GlcNAc) ${ }_{4}$ as with nascent chitin: Fig. 4]. It is, furthermore, based on the tenet that there should be grossly comparable rates of colour release from any of the pseudochito-oligomers with $n \geqslant 4$ if catalysis were to occur by a random-type of hydrolysis, but no colour-yielding activity with evennumbered analogues, if there were a processive cleavage of the substrates. Hence, the chitinase preparations with $V_{\mathrm{e}} / V_{\mathrm{t}}>1$, which were devoid of $\beta$-GlcNAc'ase, bring about substrate degradation by an endo-type of mechanism, and this is probably also true for the chitinases with lower elution volumes.

Quantitatively, however, this experimental model for the assessment of endo-activity is of limited predictive value and should, therefore, not be overstressed. It does not account for the decreased binding likely to occur with the minimum-chain-length substrate accepted by the enzyme, since, in this case, the negative influence of the unnatural chromophor mimicking the reducing end of the chito-oligomer will be highest. Moreover, the model does not allow for the possibility of (further) discrimination of the 3,4-DNP-releasing step if the maximum catalytic activity of the chitinase can be satisfied with chitobiosyl units more remote from the phenyl residue. This notwithstanding, the results are such as to indicate that both of these phenomena occur (Table 1).

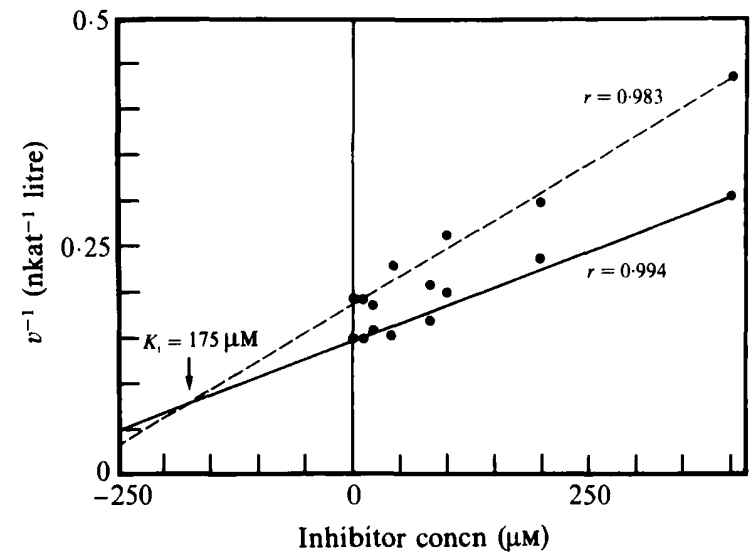

Fig. 9. Kinetics of inhibition of chitinase by $N, N^{\prime}$-diacetylchitobiono1,5-lactone oxime (Dixon plot of activity; three experiments). 3,4DNP-(GlcNAc) $)_{4}(-, 160 \mu \mathrm{M} ;---, 80 \mu \mathrm{M})$ served as the substrate. The data are from an experiment with chitinases 0.87-1.13.

Inhibition. All chitinases, assayed with 3,4-DNP(GlcNAc) ${ }_{4}$, were slightly inhibited by $N, N^{\prime}$-diacetylchitobiose; the $I_{50}$ value amounted to about $20 \mathrm{mM}$ (the highest concentration tested); the inhibitory effect of GlcNAc was extremely small $(10 \%$ at $20 \mathrm{~mm})$.

An analogue of chitobiose, $N, N^{\prime}$-diacetylchitobiono1,5-lactone oxime, turned out to be a novel competitive inhibitor of chitinase with a $K_{\mathrm{i}}$ value of around $175 \mu \mathrm{M}$ (Fig. 9). All chitinases behaved similarly. The effect of the corresponding monomer, $N$-acetylglucosaminono1,5 -lactone oxime, was negligible $(10-15 \%$ reduction of activity at $10 \mathrm{~mm}$, the highest concentration tested), irrespective of the $V_{\mathrm{e}} / V_{\mathrm{t}}$ values of the chitinase pools. For $\beta$-GlcNAc'ase, the simple lactone is, however, a potent inhibitor (Horsch et al., 1991).

\section{Discussion}

A new procedure for the production of fast-growing and morphologically homogeneous exponential phase mycelium of $M$. rouxii

The method described here for the cultivation of $M$. rouxii in its mycelial form yields material of high reproducibility with respect to both morphology and growth rate (Figs 1 and 2). Such information has not been available before. The procedure was characterized by high $\mu_{\max }$ values $\left[t_{\mathrm{d}}\left(28^{\circ} \mathrm{C}\right)=67 \mathrm{~min}\right.$ : see also Furter, 1985]. The fact that this material has now been shown to possess a complex chitinolytic system and that an analogous procedure is available for the production of yeast cells of the fungus $\left[t_{\mathrm{d}}\left(28^{\circ} \mathrm{C}\right)=83 \mathrm{~min}\right.$ : Furter, 1985] should make this system particularly attractive for 
investigations into the functional significance of exponential phase chitinolysis in hyphal vs budding type of growth. It should also facilitate the assignment of chitinases to their sites of action and to their respective chitin synthetase partners (see below).

\section{A biochemical characterization of the chitinolytic system} of exponentially growing mycelium

Multiplicity of chitinases. The chitinolytic system of the growing hypha described here is considerably more elaborate than envisaged previously (Lopez-Romero et al., 1982; Zarain-Herzberg \& Arroyo-Begovich, 1983; Humphreys \& Gooday, 1984; Pedraza-Reyes \& LopezRomero, 1989). The simultaneous presence of chitinase isoforms, which occurs also in Saccharomyces cerevisiae (Correa et al., 1982), is not a peculiarity of fungi, since it has been described for bacteria (Fuchs et al., 1986), insects (Koga et al., 1983) and green plants (Roby \& Esquerre-Tugaye, 1987; Legrand et al., 1987; Majeau et al., 1990). This diversity of chitinase species could be the result of a differential processing of one primary translation product, or of a simultaneous expression of more than one chitinase gene. Circumstantial evidence for processing derives from the assumption that the chitinase protein would be released by the growing hypha on to its surface and would, thus, probably have undergone a series of post-translational modifications along the secretory pathway, including glycosylation and limited proteolysis (cf. Yan et al., 1989; Balch, 1989). Indeed, there is co-occurrence of a large-particle-bound, highly latent species (chitinase $0.25 ; 5000 \mathrm{kDa}$, corresponding to about 100S; Figs 5 and 7), a small-particulate (about $500 \mathrm{kDa} ; 16 \mathrm{~S}$ ), less zymogenic form (chitinase 0.55 ; Fig. 7 , results in text and unpublished data) and various soluble chitinases (chitinases $0 \cdot 75-1 \cdot 60$; Fig. 7), some of which are stimulated by limited proteolysis. Multiple genes could, nevertheless, also contribute to the diversity of chitinases produced. In other organisms, e.g. the bacterium Serratia marcescens (Jones et al., 1986) and some plants (Broglie et al., 1986; Hooft van Huisduijnen et al., 1987), up to four chitinase genes have been found to be transcriptionally active simultaneously. It appears improbable, therefore, that the multiplicity of chitinases in extracts from exponential phase mycelium would be an artefact resulting from inadvertantly effecting uncontrolled proteolysis of one single chitinase during its isolation.

By partial analogy with the situation holding for the endo-1,4- $\beta$-glucanase system (Wood, 1985) the different chitinases might have slightly differing preferences for substrates, such as highly crystalline vs largely amorphous, preformed vs nascent, and longer vs shorter chitin chain lengths. Indeed, the (relative) ability to digest preformed chitin is higher for soluble chitinases with $V_{\mathrm{e}} / V_{\mathrm{t}} \leqslant 1$ (cf. Figs 3 and 4). Furthermore, the lack of resolution of the $0.70-1.50$ region of the chitinase profile with the less exacting chito-oligomer analogue substrate 3,4-DNP-(GlcNAc) ${ }_{4}$ (Figs 4 and 7), also suggests that the various soluble chitinases have small functional differences. These may well concern preferences in chain length and, hence, also in the ratio of transglycosylating to purely hydrolytic activity. This ratio can be surmised to be higher with chitin and large chito-oligomers, owing to the lower diffusibility of the leaving group, than with a substrate barely meeting the minimum requirement for binding (see Table 1 and results in text; for an explanation of the relationship between enzyme-catalysed glycoside hydrolysis and glycosyl transfer to an acceptor other than water, see Sinnott, 1987). Nevertheless, a definite assignment of the individual chitinases to these different functions requires a separate investigation with the highly purified enzymes.

Co-occurrence of chitinase with $\beta$-GlcNAc'ase. The simultaneous presence of chitinase and $\beta$-GlcNAc'ase (Figs 6 and 7; main peak at $V_{\mathrm{e}} / V_{\mathrm{t}}=0.65$ ) is in keeping with the general belief that the latter represents an obligate component of any system effecting chitinolysis in vivo ( $\mathrm{Kramer} \& \mathrm{Koga}, 1986$ ). Besides catalysing the final step in the degradation of the chitin polymer, $\beta$ GlcNAc'ase may play also a regulatory role in chitinolysis. This has been thought to consist in preventing inhibition of the chitinase by the end product $N, N^{\prime}$ diacetylchitobiose (cf. Molano et al., 1977). There is, nevertheless, little evidence for this to occur in the growing hypha, since inhibition by the dimer of any of the chitinase forms present in the extract was small $\left(I_{50}\right.$ about $20 \mathrm{~mm}$ ). However, synergism, sui generis, in the action of the two enzymes in degrading the native substrate, similar to the one postulated for the "chitinase plus $\beta$-GlcNAc'ase tandem binary enzyme system' of insect moulting fluid (Fukamizo \& Kramer, 1985), might be part of an efficient control system for chitinolysis in fungi. This assumption could explain why the main (composite) chitinase peak was apparently shifted towards lower $V_{\mathrm{e}} / V_{\mathrm{t}}$ values and the chitinase 0.55 entity merged with this, when chitin, instead of the soluble chito-oligomer, served to monitor eluate fractions (cf. Figs 4 and 3), since such synergism would be most pronounced in chitinase fractions with high $\beta$-GlcNAc'ase contents. Mechanistically, this synergism could involve a stereocontrolled transfer of chitobiosyl units to closely associated $\beta$-GlcNAc'ase. Indeed, chitobionolactone oxime, mimicking chitobiose in statu nascendi, is a fairly good inhibitor of chitinase (Fig. 9), whereas free chitobiose is not (see above).

Although $\beta$-GlcNAc'ase is generally considered to be 
lysosomal, growing fungi secrete it (Sullivan et al., 1984; Linder, 1987). In the exponential phase hypha of $M$. rouxii the enzyme is tightly bound to the wall (Linder, 1987). In addition to the main $\beta$-GlcNAc'ase entity, another form of the enzyme is associated with a $16 \mathrm{~S}$ particle (whether isolated from walls or obtained by dissociation of chitosomes according to Hänseler $e t$ al., 1983) (Horsch, 1991). Partial overlapping of the elution profiles of the void volume and the $16 \mathrm{~S}$ as well as the major soluble $\beta$-GlcNAc'ase species is, therefore, likely to be the cause of the oblique shape of the $\beta$-GlcNAc'ase peak displayed under the gel permeation conditions used here (Fig. 6). Finally, two tiny peaks of $\beta$-GlcNAc'ase activity were regularly observed in the $V_{\mathrm{e}} / V_{\mathrm{t}}=1 \cdot 30-1.50$ region (Fig. 6). As with chitinase, the simultaneous presence of isoforms of $\beta$-GlcNAc'ase is not a speciality of the fungal organism, being displayed also by plants and animals (Carratù et al., 1985; Beccari et al., 1988).

Classification of exponential phase chitinases. Using various operational criteria, the soluble chitinases of the exponential phase hypha represent two groups. Members of class $\mathrm{A}$, with $V_{\mathrm{e}} / V_{\mathrm{t}}>1$, undergo an anomalous retardation upon gel-permeation chromatography and display microheterogeneity, are anionic at their $\mathrm{pH}$ activity optimum, can be proteolytically activated, and have a negligible ability to degrade colloidal chitin (Figs 3, 4, 7 and 8). With this set of characteristics class $\mathrm{A}$ chitinases are not only distinct from the chitinases constituting class $\mathrm{B}\left(V_{\mathrm{e}} / V_{\mathrm{t}}<1\right)$ but also from most chitinases in general.

\section{Functional significance of the chitinolytic system of exponential growing mycelium: an hypothesis}

The complex chitinolytic system (Fig. 7) of hyphae growing at $\mu_{\max }$ in a chitin-free medium is present at a time when the latter still contains a large proportion of the glucose supplied. Therefore, the enzymes concerned must be synthesized under a severe regime of catabolite repression and, hence, are clearly constitutive - in contrast to chitinolytic enzymes induced upon growth on chitin, under carbon limitation or during senescence (Rosenberger, 1979; Reyes et al., 1988). Since M. rouxii hyphae generally are non-septate, especially under the experimental conditions employed, the only potential sites of growth-associated chitinolysis are the wall areas at places of developing laterals and, on the BartnickiGarcia (1973) hypothesis, at the hyphal apices. The transformation of a localized region of the hyphal tube into a new tip evidently requires loosening of the microfibrillar network at the presumptive site of branching, a situation which inherently encompasses the potentiality of excess softening of the wall and, thence, bursting of the cell following the so-induced influx of water. Therefore, it must be inferred that this chitinolysis is subjected to tight regulation.

A speculative scheme for the controlled lysis of chitin through the concerted action of chitinase, $\beta$-GlcNAc'ase and chitin synthetase is depicted in Fig. 10. This hypothesis is based on premisses (i)-(v).

(i) The reaction mechanism of $\beta$-glycosidases in general (Sinnott, 1987) and chitinase in particular (Usui et al., 1987).

(ii) The characteristics of the chitinolytic system of growing/branching hyphae as outlined here.

(iii) Chitin synthetase being an UDP-GlcNAc transferase with chitin (presumably enzyme-bound: $c f$. Duran \& Cabib, 1978) as the (final) acceptor.

(iv) Regulatory properties of chitin synthetase, among which are its partial latency and allosteric stimulation by GlcNAc (cf. Gooday, 1983; Cabib, 1987; Horsch, 1991).

(v) The observation that for each size-type of chitinase, large and small particulate as well as soluble ones, chitin synthetase (Figs 3-5) and $\beta$-GlcNAc'ase (Fig. 6; Linder, 1987; Horsch, 1991) co-occur.

At the strictly enzymological level, the suggested system involves (1) co-operation between chitinase molecules, (2) tandem action of chitinase and $\beta$ GlcNAc'ase, (3) allosteric activation of chitin synthetase and (4) polymerization of GlcNAc residues and chainlength restriction of nascent chitin by the action of chitinase (for the few notions, largely hypothetical, regarding the mechanism of termination of polysaccharide elongation, see Robyt, 1979; Stoddart, 1984; James et al., 1985; Cabib, 1987). At the cellular level, the action of these enzymes is integrated as shown in Fig. 10 (steps 1-4).

(1) Co-operation of chitinase molecules in a medium densely packed with chitin results in a high incidence of transglycosylation events. The onset of wall-loosening would, thus, be smooth, involving not only a breaking of chitin chains, but also a regeneration of new ones. This situation allows a subtle turgor-mediated increase in wall surface in a dynamic manner.

(2) With chitinolysis proceeding, the proportion of transglycosylation events will be decreased, and the concentration of short-chain products, including chitobiose, accordingly increased. Thus, $\beta$-GlcNAc'ase will be provided with its substrate.

(3) The transfer (likely to be stereo-controlled: Horsch, 1991) of GlcNAc to its allosteric site on chitin synthetase and the conformational change thus effected would allow full-capacity binding of UDP-GlcNAc.

(4) Insertion of chitin into or deposition onto the stretched wall.

An implication inherent in the scheme outlined is that any chitin - whether nascent (probably one or two 


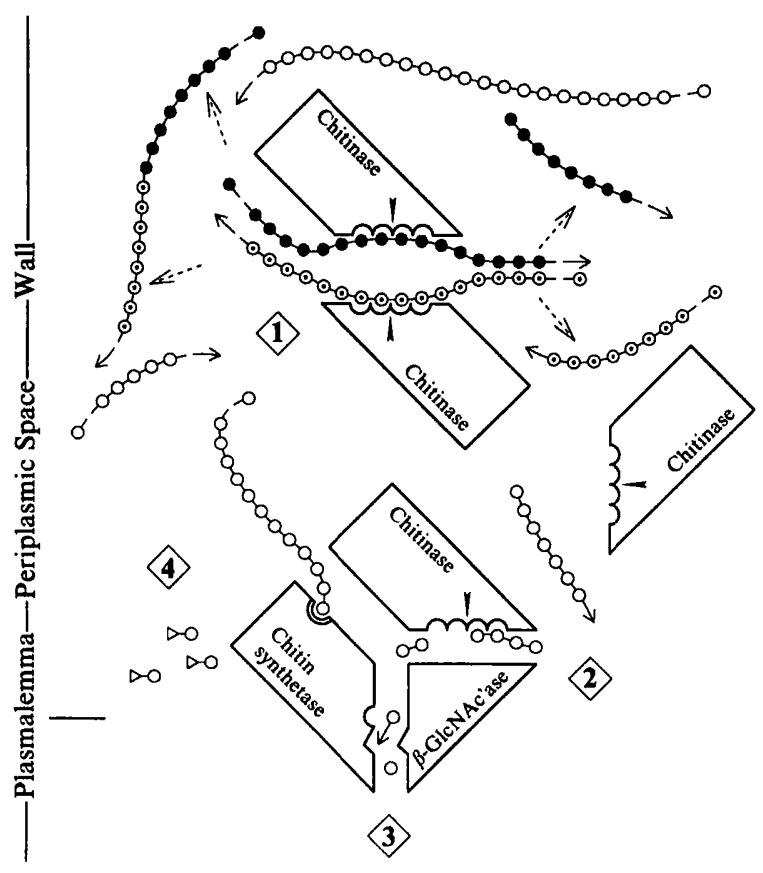

Fig. 10. Diagrammatic representation of the function of the triple integrated enzyme system consisting of chitinase, $\beta$-GlcNAc'ase and chitin synthetase that provides for controlled chitin metabolism at the place of hyphal branch initiation: an hypothesis. O, GlcNAc; $\triangleright O$, UDP-activated GlcNAc; O--O-O-O- $\rightarrow$, chitin; the sign --O marks the non-reducing end and $\rightarrow$ points to the reducing end of the polymer; reducing GlcNAc units generated through the hydrolytic action of chitinase or $\beta$-GlcNAc'ase are shown as $O \rightarrow$. The active sites of the enzymes are marked as U (chitinase), $\sim$ ( $\beta$-GlcNAc'ase) and 7 (chitin synthetase). $\longrightarrow$, Site of hydrolytic attack of chitinase; allosteric site of chitin synthetase for GlcNAc. To better illustrate the transglycosylation event, the GlcNAc residues of the two chains between which transglycosylation is depicted to take place are tagged differently $(O, O)$. The integrated action of this triple complex of enzymes encompasses four steps: (1) breakdown and remodelling of chitin chains through the combined transglycosylating and hydrolytic activity of chitinase; (2) progressive lysis of both preformed chitin and chitin chains derived from step (1) as well as of chito-oligomers, with increasing amounts of the chitobiose substrate becoming available for $\beta$-GlcNAc'ase ; (3) allosteric activation of chitin synthetase by the final product of chitinolysis, GlcNAc; (4) de novo synthesis of chitin from UDP-activated GlcNAc. (1)-(4) are not thought to be single, separate events, but to occur quasi-simultaneously, the time-lapse of the preceeding overlapping with the onset of the following. An approximate indication is given of the spatial arrangement of the enzymes and their substrates at the cell surface.

molecular chains: Hänseler et al., 1983) or crystalline (as thin fibrils) - that is displaced to the domain of active chitinase at the emerging lateral should undergo remodelling according to step 1 of the scheme (Fig. 10). This is equivalent to controlling the amount of chitin deposited, a requirement which must be met likewise at the growing apex, as is a need for localized degradation of chitin (Burnett, 1979; see, however, Wessels et al., 1990). The scheme presented may, therefore, hold not only for branch initiation, but may also be of heuristic value for the unravelling of the role that chitinolysis might play in hyphal tip growth.

Any regulatory measure allowing the sequence of events to operate effectively only when the components of the integrated triple enzymes system presented are ready to act in concert would function as a kind of superimposed overall control. This could consist in the proenzyme/enzyme conversion not only of chitin synthetase, but also of chitinase and $\beta$-GlcNAc'ase (Horsch, 1991). A type A chitinase could co-operate most closely with $16 \mathrm{~S}$-chitin synthetase as well as with the $\beta$ GlcNAc'ase physically associated with it (Horsch, 1991). Indeed, the chitinases of this group display very little activity with preformed chitin (Figs 3 and 4), and their unusually high affinity to a viscous dextran gel structure may also be construed as evidence for the periplasmic space as their locus operandi. Preformed chitin, on the other hand, would be acted upon by nonzymogenic chitinase, i.e. type B chitinase. This situation appears to require a mechanism both for allowing the 'safe' transport of fully active chitinase through the periplasmic space, where it would, otherwise, readily attack easily accessible chitin [its activity is primarily substrate-limited (Fig. 4 and section on Latency)], as well as for its instalment at the appropriate site within the densely packed wall fabric. The need to resolve such a translocation problem could, however, be obviated if, in the course of controlled chitin synthesis/chitin lysis, type A chitinase became entrapped into its product and transformed into type B chitinase. Considering the glycoprotein and secretory nature of chitinases in general, the phenomenon of post-translational modification following secretion as well as the presence of appropriate hydrolytic enzymes in the wall of the growing hypha (Rosenberger, 1979), this could be effected by (further) proteolysis as well as by deglycosylation. But this must be the subject of further investigations.

This work has been supported by the Swiss National Science Foundation (grants nos 3.292-0.85 and 31-26961.89), the Foundation for Scientific Research at the University of Zürich (project 1985), and the Agricultural and Food Research Council of Britain. A research grant from the Royal Society of London is also kindly acknowledged. Part of the investigation reported here was carried out during a sabbatical stay of D.M.R. at the University of Aberdeen, and part of the paper was written during a leave of absence at the University of Oxford as a Visiting Scholar of Green College. It is a particular pleasure to thank Sir John Burnett, Plant Sciences, Oxford, for many stimulating conversations and for critically reading the manuscript. Further acknowledgements go to colleagues from the Universities of Zürich and Aberdeen: to Professor Vasella for providing GlcNAcbased oximes, Dr H.P. Ruffner for FPLC runs, Mr U. Jauch for microscope work, and Dr L. Hoesch as well as Dr J.I. Prosser for useful discussions. 


\section{References}

Aribisala, O. A. \& Gooday, G. W. (1978). Properties of chitinase from Vibrio alginolyticus, as assayed with the chromogenic substrate 3,4-dinitrophenyl tetra- $N$-acetylchitotetraoside. Biochemical Society Transactions 6, 568-569.

BALCH, W. E. (1989). Biochemistry of interorganelle transport. A new frontier emerges from versatile in vitro model systems. Journal of Biological Chemistry 264, 16965-16968.

Ballardie, F. W., Capon, B., Cuthbert, M. W. \& Dearie, W. M. (1977). Some studies on catalysis by lysozyme. Bioorganic Chemistry 6, 483-509.

Barrett-Bee, K. \& Hamilton, M. (1984). The detection and analysis of chitinase activity from the yeast form of Candida albicans. Journal of General Microbiology 130, 1857-1861.

Barrett-Bee, K. J., Lees, J. \& Henderson, W. (1982). Variation in the activities of enzymes associated with cell wall metabolism during a growth cycle of Candida albicans. FEMS Microbiology Letters 15, 275-278.

BARTNICKI-GARCIA, S. (1973). Fundamental aspects of hyphal morphogenesis. Symposia of the Society for General Microbiology 23, 245-267.

BARTNICKI-GARCIA, S. \& NICKERSON, W. J. (1962). Induction of yeastlike development in Mucor by carbon dioxide. Journal of Bacteriology 84, 829-840.

Bartnicki-Garcia, S., Bracker, C. E., Reyes, E. \& Ruiz-Herrera, J. (1978). Isolation of chitosomes from taxonomically diverse fungi and synthesis of chitin microfibrils in vitro. Experimental Mycology 2,173-192.

BeCCARI, T., Orlacchio, A. \& Sterling, J. (1988). Identification of $\beta$ - $N$-acetylhexosaminidase $\mathrm{A}$ in mouse tissue with the fluorigenic substrate 4-methylumbelliferyl- $\beta-N$-acetylglucosamine 6 -sulphate. Biochemical Journal 252, 617-620.

Beer, D., Maloisel, J.-L., Rast, D. M. \& Vasella, A. (1990) Synthesis of 2-acetamido-2-deoxy-D-gluconhydroximolactone- and chitobionhydroximolactone-derived $N$-phenylcarbamates, potential inhibitors of $\beta-N$-acetylglucosaminidase. Helvetica Chimica Acta 73, 1918-1922.

Borooah, J., Leaback, D. H. \& Walker, P. G. (1961). Studies on glucosaminidase. Substrates for $N$-acetyl- $\beta$-glucosaminidase. Biochemical Journal 78, 106-110.

BRADFORD, M. M. (1976). A rapid and sensitive method for the quantitation of microgram quantities of protein using the principle of protein-dye binding. Analytical Biochemistry 72, 248-254.

Broglie, K. E., Gaynor, J. J. \& Broglie, R. M. (1986). Ethyleneregulated gene expression: molecular cloning of the genes encoding an endochitinase from Phaseolus vulgaris. Proceedings of the National Academy of Sciences of the United States of America 83, 6820-6824.

BURNETT, J. H. (1979). Aspects of the structure and growth of hyphal walls. In Fungal Walls and Hyphal Growth, pp. 1-25. Edited by J. H. Burnett \& A. P. J. Trinci. Cambridge: Cambridge University Press.

CABIB, E. (1987). The synthesis and degradation of chitin. Advances in Enzymology 59, 59-101.

Carratù, G., Colacino, C., Conti, S. \& Giannattasio, M. (1985) $\beta$ - $N$-Acetylglucosaminidase and $\beta$-galactosidase from aleurone layers of resting wheat grains. Phytochemistry 24, 1465-1469.

Correa, J. U., Elango, N., Polacheck, I. \& Cabib, E. (1982). Endochitinase, a mannan-associated enzyme from Saccharomyces cerevisiae. Journal of Biological Chemistry 257, 1392-1397.

Coudron, T. A., Kroha, M. J. \& IGNofFo, C. M. (1984). Levels of chitinolytic activity during development of three entomopathogenic fungi. Comparative Biochemistry and Physiology 79BN, 339-348.

DURAN, A. \& CABIB, E. (1978). Solubilization and partial purification of yeast chitin synthetase. Confirmation of the zymogenic nature of the enzyme. Journal of Biological Chemistry 253, 4419-4425.

Fuchs, R. L., MCPherson, S. A. \& Drahos, D. J. (1986). Cloning of Serratia marcescens gene encoding chitinase. Applied and Environmental Microbiology 51, 504-509.

FUKAMIZO, T. \& KRAMER, K. J. (1985). Mechanism of chitin hydrolysis by the binary chitinase system in insect moulting fluid. Insect Biochemistry 15, 141-145.
FURTER, R. (1985). Die Chitinsynthese des dimorphen Zygomyceten Mucor rouxii. $\mathrm{PhD}$ thesis, University of Zürich, Switzerland.

GoodAY, G. W. (1983). The microbial synthesis of cellulose, chitin and chitosan. Progress in Industrial Microbiology 18, 85-127.

HäNSEleR, E., NYHLÉn, L. E. \& RAST, D. M. (1983). Dissociation and reconstitution of chitosomes. Biochimica et Biophysica Acta 745, 121133.

Hooft van Huisduijnen, R. A. M., Kauffmann, S., Brederode, F. T., Cornelissen, B. J. C., Legrand, M., Fritig, B. \& Bol, J. F. (1987). Homology between chitinases that are induced by TMV infection of tobacco. Plant Molecular Biology 9, 411-420.

HoRSCH, M. (1991). N-Acetylglucosaminonoxime als Modulatoren von Chitinsynthetase und von chitinolytischen Enzymen. Experimente mit Mucor rouxii. $\mathrm{PhD}$ thesis, University of Zürich, Switzerland.

Horsch, M., Hozsch, L., Vasella, A. \& Rast, D. M. (1991). $N$ Acetylglucosaminono-1,5-lactone oxime and the corresponding (phenylcarbamoyl)oxime - novel inhibitors of $\beta$ - $N$-acetylglucosaminidase. European Journal of Biochemistry 197, 815-818.

Humphreys, A. M. \& Gooday, G. W. (1984). Properties of chitinase activities from Mucor mucedo: evidence for a membrane-bound zymogenic form. Journal of General Microbiology 130, 1359-1366.

JAMES, D. W., JR, Preiss, J. \& Elbein, A. D. (1985). Biosynthesis of polysaccharides. In The Polysaccharides, vol. 3, pp. 107-207. Edited by G. O. Aspinall, Orlando: Academic Press.

Jones, J. D. G., Grady, K. L., Suslow, T. V. \& Bedbrook, J. R. (1986). Isolation and characterization of genes encoding two chitinase enzymes from Serratia marcescens. EMBO Journal 5, 467473

KOGA, D., JiLKA, J. \& KRAMER, K. J. (1983). Insect endochitinases: glycoproteins from moulting fluid, integument and pupal haemolymph of Manduca sexta. Insect Biochemistry 13, 295-305.

Kramer, K. J. \& KogA, D. (1986). Insect chitin. Physical state, synthesis, degradation and metabolic regulation. Insect Biochemistry 16, 851-877.

Legrand, M., KauffmanN, S., Geoffroy, P. \& Fritig, B. (1987). Biological function of pathogenesis-related proteins: four tobacco pathogenesis-related proteins are chitinases. Proceedings of the National Academy of Sciences of the United States of America 84, 6750-6754.

LINDER, C. (1987). Reinigung und Bestimmung von Charakteristika der $\beta$ - $N$-Acetylglucosaminidase aus Mucor rouxii. MSc thesis, University of Zürich, Switzerland.

Lopez-Romero, E., Ruiz-Herrera, J. \& Bartnicki-Garcia, S. (1982). The inhibitory protein of chitin synthetase from $\mathrm{Mucor}$ rouxii is a chitinase. Biochimica et Biophysica Acta 702, 233-236.

Majeau, N., Trudel, J. \& Asselin, A. (1990). Diversity of cucumber chitinase isoforms and characterization of one seed basic chitinase with lysozyme activity. Plant Science 68, 9-16.

Molano, J., DURAN, A. \& CABIB, E. (1977). A rapid and sensitive assay for chitinase using tritiated chitin. Analytical Biochemistry 83, 648656.

Pedraza-Reyes, M. \& Lopez-Romero, E. (1989). Purification and some properties of two forms of chitinase from mycelial cells of Mucor rouxii. Journal of General Microbiology 135, 211-218.

Reyes, F., Calatayud, J. \& Martinez, M. J. (1988). Chitinolytic activity in the autolysis of Aspergillus nidulans. FEMS Microbiology Letters 49, 239-243.

Robbins, P. W., Albright, C. \& Benfield, B. (1988). Cloning and expression of a Streptomyces plicatus chitinase (chitinase-63) in Escherichia coli. Journal of Biological Chemistry 263, 443-447.

Rober tSON, N. F. (1968). The growth process in fungi. Annual Review of Phytopathology 6, 115-136.

Roby, D. \& Esquerre-Tugaye, M. T. (1987). Purification and some properties of chitinases from melon plants infected by Colletotrichum lagenarium. Carbohydrate Research 165, 93-104.

RoBYT, J. F. (1979). Mechanisms involved in the biosynthesis of polysaccharides. Trends in Biochemical Sciences 4, 47-49.

ROSENBERGER, R. F. (1979). Endogenous lytic enzymes and wall metabolism. In Fungal Walls and Hyphal Growth, pp. 265-277. Edited by J. H. Burnett \& A. P. J. Trinci. Cambridge: Cambridge University Press. 
Ruiz-Herrera, J. \& Bartnicki-Garcia, S. (1976). Proteolytic activation and inactivation of chitin synthetase from Mucor rouxii. Journal of General Microbiology 97, 241-249.

SinNoTt, M. L. (1987). Glycosyl group transfer. In Enzyme Mechanisms, pp. 259-297. Edited by M. Page. Letchworth: Royal Society of Chemistry.

STODDART, R. W. (1984). The Biosynthesis of Polysaccharides, pp. 181182. London: Croom Helm.

Sullivan, P. A., McHugh, N. J., Romana, L. K. \& Shepherd, M. G. (1984). The secretion of $N$-acetylglucosaminidase during germ-tube formation in Candida albicans. Journal of General Microbiology 130, 2213-2218.

SUND, H. \& WEBER, K. (1963). Untersuchungen über milchzuckerspaltende Enzyme. XIII. Grösse und Gestalt der $\beta$-Galactosidase aus $E$. coli. Biochemische Zeitschrift 337, 24-34.

Usui, T., HaYashi, Y., Nanjo, F., Sakai, K. \& Ishido, Y. (1987). Transglycosylation reaction of a chitinase purified from Nocardia orientalis. Biochimica et Biophysica Acta 923, 302-309.
Wessels, J. G. H. (1984). Apical hyphal wall extension. Do lytic enzymes play a role? In Microbial Cell Wall Synthesis and Autolysis, pp. 31-42. Edited by C. Nombela. Amsterdam: Elsevier Science Publishers.

Wessels, J. G. H. (1986). Cell wall synthesis in apical hyphal growth International Review of Cytology 104, 37-79.

Wessels, J. G. H., Mol, P. C., Sietsma, J. H. \& Vermeulen, C. A (1990). Wall structure, wall growth, and fungal morphogenesis. In Biochemistry of Cell Walls and Membranes in Fungi, pp. 81-95. Edited by P. J. Kuhn, A. P. J. Trinci, M. J. Jung \& M. W. Goosey. Berlin: Springer-Verlag.

WooD, T. M. (1985). Properties of cellulolytic enzyme systems. Biochemical Society Transactions 13, 407-410.

YAN, S. C. B. GRINNell, B. W. \& Wold, F. (1989). Post-translational modifications of proteins: some problems left to solve. Trends in Biochemical Sciences 14, 264-268.

Zarain-Herzberg, A. \& Arroyo-Begovich, A. (1983). Chitinolytic activity from Neurospora crassa. Journal of General Microbiology 129, 3319-3326. 